1 Fundação Oswaldo Cruz (Fiocruz), Escola Nacional de Saúde Pública Sergio Arouca (Ensp) - Rio de Janeiro (RJ), Brasil. jovisdi@gmail.com

\section{Educação popular e saúde mental: aproximando saberes e ampliando o cuidado}

\author{
Popular education and mental health: bringing knowledge together \\ and expanding healthcare
}

João Vinícius dos Santos Dias', Paulo Duarte de Carvalho Amarante1

DOI: $10.1590 / 0103-1104202213213$

\begin{abstract}
RESUMO O texto discute as possíveis aproximações entre a educação popular e a saúde mental, na perspectiva da atenção psicossocial, nos âmbitos epistemológicos, prático-assistencial e institucional. A partir de um breve resgate histórico do campo da educação popular, em particular no Brasil, e dialogando com a perspectiva de Victor Valla, identifica a influência, muitas vezes difusa, da educação popular nos serviços que têm uma proximidade maior com a vida comunitária, como os Centros de Atenção Psicossocial e os Consultórios na Rua. Discute também a aproximação paradigmática entre a saúde mental e a educação popular no estabelecimento de uma nova relação com o conhecimento, em que os mitos da neutralidade, do distanciamento crítico e da autonomia da ciência moderna são colocados em questão. No campo institucional, identifica um movimento de convergência entre saúde mental e educação popular no âmbito das políticas públicas em saúde, principalmente, a partir do fortalecimento da atenção básica como porta de entrada e centro articulador do Sistema Único de Saúde. Por fim, aponta as contribuições da aproximação entre as duas áreas para os atuais movimentos de resistência às crescentes ameaças à democracia, aos direitos humanos e à defesa da vida.
\end{abstract}

PALAVRAS-CHAVE Educação popular. Saúde mental. Atenção psicossocial.

ABSTRACT The text discusses the possible connections between popular education and mental health from the perspective of psychosocial care in the epistemological, practical-assistance, and institutional fields. Based on a brief historical review of the field of popular education, particularly in Brazil, and considering Victor Valla's perspective, the study identifies the often diffuse influence of popular education in services that have a closer relationship with the communal life, such as the Psychosocial Care Centers (Caps) and the Street Clinics (CnaR). This work also discusses the paradigmatic approach between mental health and popular education in the establishment of a new relationship with knowledge itself, where the myths of neutrality, of critical distance, and of the autonomy of modern science are questioned. In the institutional field, the text identifies a convergent movement between mental health and popular education in the context of public health policies, mainly by strengthening Primary Health Care as the gateway and organizer of the Brazilian Public Health System (SUS). Finally, the article points out the contributions of the approximation between these two areas for the current movements of resistance to the growing threats to democracy, human rights, and the defense of life.

KEWORDS Population education. Mental health. Psychosocial care. 


\section{Introdução}

O presente texto tem como proposta discutir alguns dos possíveis diálogos entre saúde mental e educação popular nos âmbitos epistemológico, prático-assistencial e institucional, assim como apontar caminhos para a construção de uma perspectiva ampliada de cuidado, valorizando as múltiplas formas de ser e estar no mundo.

No entanto, por que relacionar educação popular e saúde mental? Partimos da constatação de que há uma lacuna nas pesquisas e produções acadêmicas acerca das possíveis interlocuções entre os campos da educação popular e da saúde mental, na perspectiva da atenção psicossocial, embora ambos tenham se desenvolvido significativamente nas últimas décadas no Brasil.

Consideramos ainda que a educação popular está presente em muitos processos cotidianos dos serviços de saúde e de seus profissionais embora não seja nomeada como tal. Há uma influência da educação popular, que ocorre de forma difusa, especialmente nos serviços que tem proximidade com a vida comunitária, como as unidades de atenção básica e a Estratégia Saúde da Família (ESF). No campo da saúde mental, em especial nos serviços guiados pela lógica da atenção psicossocial - os quais têm no conceito de território uma dimensão estruturante do trabalho como os Centros de Atenção Psicossocial (Caps) e os Consultórios na Rua (CnaR) -, essa influência também se faz presente em ações e estratégias de cuidado, embora dificilmente seja reconhecida ou considerada enquanto educação popular.

Outra importante aproximação entre os dois campos é o caráter contra-hegemônico de ambos. Para Paulo Freire, uma das maiores referências do campo da educação popular no Brasil e no mundo, todo conhecimento é ideológico ${ }^{1}$. Assim, o que diferencia os variados conhecimentos é a que tipo de ideologia eles estão vinculados: se a uma lógica de solidariedade ou a serviço de interesses privativos, se em defesa da emancipação ou da manutenção das opressões, se a favor da pluralidade das formas de ser ou do tolhimento das singularidades, em suma, se em defesa da ampliação de diferentes formas de viver e estar no mundo ou de seu cerceamento.

Nesse sentido, a educação popular pode ser considerada um movimento contra-hegemônico aos processos de colonização e silenciamento de vozes historicamente oprimidas: seja pela resistência às formas coloniais de dominação cultural, política e econômica; pela produção de um pensamento que rompa com a subalternização dos saberes e experiências de sujeitos sociais historicamente marginalizados; pelo fortalecimento das lutas sociais de trabalhadores(as), mulheres, negros(as), população LGBTQIA+, refugiados(as), entre outros; e, também, pela construção de metodologias e formas de participação que viabilizem o protagonismo e a valorização dos conhecimentos destes sujeitos sociais.

Já no campo da saúde mental no Brasil, vivenciamos, desde o surgimento do movimento da reforma psiquiátrica, em meados da década de 1970, uma rica pluralidade de vozes e produções. Consideramos que o paradigma da atenção psicossocial, referência prático-teórica construída a partir da reforma, é também potencialmente contra-hegemônico ao distanciar-se de uma perspectiva de saúde mental pautada exclusivamente na racionalidade biomédica, representada pela psiquiatria e pela hospitalização, que historicamente foram consolidadas como tecnologias de cuidado hegemônicas ${ }^{2}$.

A atenção psicossocial busca ampliar as possibilidades de cuidado e assistência, ultrapassando inclusive o campo da saúde mental stricto sensu e dialogando com diferentes saberes e áreas de conhecimento. Assim, o fortalecimento da perspectiva da atenção psicossocial aponta para o entendimento de que o próprio processo de reforma psiquiátrica não se resume à psiquiatria, mas tem base em áreas diversas, como, por exemplo, a filosofia, as ciências sociais, as artes e o direito; e que, 
portanto, precisa dialogar de forma ampliada com diversos saberes e conhecimentos.

A fim de identificarmos os diálogos entre o campo da saúde mental e o da educação popular, propomos um breve resgate histórico da educação popular, em particular no Brasil, bem como a discussão de algumas das principais dimensões da proposta da atenção psicossocial em saúde mental no País. Ademais, procuraremos reconhecer possíveis contribuições da aproximação entre os dois campos para o cuidado em saúde e para o fortalecimento dos movimentos de resistência às crescentes ameaças à democracia, aos direitos humanos e à defesa da vida.

\section{Educação popular: um breve histórico}

Educação popular é uma concepção em disputa que, ao longo de diferentes momentos e contextos, foi representada por múltiplas definições e sentidos. Preiswerk ${ }^{3}$ aponta que seu caráter polissêmico pode acarretar o risco de descaracterização ou esvaziamento, como, por exemplo, na redução à diferenciação entre educação formal $\mathrm{x}$ informal e na ideia de educação para populares.

Consideramos a educação popular como uma concepção prático/teórica e uma metodologia de educação que articula diferentes saberes e práticas valorizando as dimensões da cultura e dos direitos humanos, assim como o compromisso com o diálogo e protagonismo das classes populares nas transformações sociais. Atenta à produção de desigualdades no interior do sistema capitalista e ao papel que a educação cumpre nessa dinâmica, a educação popular foi historicamente forjada no campo da organização e lutas populares por meio da ação-reflexão-ação. Assim, podemos afirmar que ela não é uma teoria que criou a prática, nem uma prática que criou uma teoria, mas, sim, o fruto dessas duas dimensões unidas por meio de um processo de 'práxis'. Na concepção de Paulo Freire, 'práxis' pode ser compreendida como a estreita relação que se estabelece entre um modo de interpretar a realidade e a vida e a consequente prática que decorre dessa compreensão levando a uma ação transformadora ${ }^{4}$.

Preiswerk ${ }^{3}$ enfatiza que a educação popular se desenvolveu intimamente ligada às lutas anticolonialistas e pela preservação da memória e da cultura dos povos indígenas. No entanto, a autora Conceição Paludo 5 aponta que a educação popular tem também raízes em diferentes experiências históricas, entre elas, o enfrentamento do capital por operários e camponeses no início do século XX, as experiências socialistas do Leste Europeu, o marxismo, a teoria de Paulo Freire, a Teologia da Libertação e o novo sindicalismo.

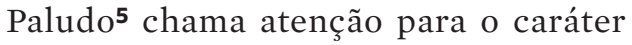
múltiplo e a dimensão global das origens da educação popular. Para ela, uma característica fundamental do campo da educação popular é o exercício crítico ao sistema societário vigente. Nessa perspectiva, a educação popular assume lugar distinto não só ao paradigma da ciência moderna, mas também aos modos de reprodução da sociedade capitalista ao propor e produzir outros modelos de sociabilidade pautados por valores alternativos ao crescente processo de acumulação, individualização e massificação da cultura de consumo ${ }^{6}$. Nesse sentido, a educação popular se caracterizou, ao longo dos anos, como uma alternativa às pedagogias e práticas liberais a serviço da manutenção das estruturas de poder político, de exploração da força de trabalho e de domínio cultural.

É importante ressaltar na definição da autora um diálogo com os apontamentos de Preiswerk ${ }^{3}$ : a ênfase na dimensão de luta e resistência intrinsicamente presente nas origens da educação popular, quando a entendemos como movimento surgido na América Latina em resposta à colonização cultural, econômica e política empreendida pelo países eurocêntricos e norte-americanos. Assim, podemos ainda identificar uma aproximação da educação popular com as teorias pós-coloniais na crítica à colonização e seus efeitos. 
No Brasil, podemos situar formalmente a educação popular, a partir do início do século $\mathrm{XX}$, por meio de experiências educativas da classe trabalhadora da cidade e do campo, da organização de escola para a classe operária com a chegada de grupos imigrantes com ideologias anarquistas e com os movimentos pela democratização da educação, a partir da década de 1920. Brandão7 destaca que as propostas de trabalho pedagógico com as classes populares nesse período, entre elas, a luta pela escola pública, as campanhas pela erradicação do analfabetismo e as experiências de educação de classe entre operários, eram originadas e produzidas a partir do repertório de ideias e práticas dos movimentos sociais dedicados à educação existentes à época.

As experiências de educação popular no País se multiplicaram, especialmente, a partir do final da década de $1950^{7}$. Nesse período, não apenas o Brasil, mas também outros países da América Latina passavam por processos ainda iniciais de industrialização, os quais começavam a produzir alterações nas relações de classe exigindo qualificação de mão de obra para o mercado de trabalho que se construía. Somam-se a isso uma crescente demanda de alfabetização a partir dos movimentos migratórios no País e uma acelerada urbanização das grandes cidades e capitais.

A proposta de educação popular que se fortaleceu nos anos posteriores era uma contraposição ao modelo até então dominante na educação e alfabetização de adultos, afirmando-se como um movimento de trabalho político com as classes populares, não se colocando como uma forma mais avançada de educação compensatória, mas como uma retotalização do projeto educativo a partir da perspectiva popular. Para Brandão ${ }^{7}$, o que tornou historicamente possível a emergência dessa concepção de educação popular foi a conjunção entre períodos de governos populistas, a produção acelerada de uma intelectualidade estudantil, universitária, religiosa e partidariamente militante e a conquista de espaços de novas formas de organização das classes populares.
Na década de 1960, a educação popular se expandiu na América Latina como projeto político e pedagógico e como movimento cultural. No Brasil, a pedagogia de Paulo Freire se tornou uma referência, e a educação popular se articulou à ação política de diversos grupos populares como intelectuais, estudantes e pessoas ligadas à igreja católica. A partir do trabalho com as classes historicamente oprimidas, como camponeses e operários, Freire construiu um método educativo baseado na realidade cotidiana de vida das pessoas se contrapondo ao que ele denominava de 'educação bancária', tecnicista e alienante'. Por intermédio de múltiplas experiências - com destaque para a ocorrida na cidade de Angicos no Rio Grande do Norte, em 1963 -, Paulo Freire conseguiu obter resultados expressivos na alfabetização de adultos, fortalecendo a ideia de que as classes populares se educam em suas próprias práticas, assim como a necessidade de construção de um projeto de País que valorizasse sua cultura contrapondo-se à dominação cultural colonialista.

Um tema central da educação popular proposta por Paulo Freire é o da crítica à opressão. A partir do pensamento freiriano, podemos falar de opressão como uma forma de funcionamento de poder. Nessa perspectiva, o oprimido - representado pelas populações consideradas periféricas como mulheres, proletários(as), negros(as) etc. - não é somente aquele ou aquela que suporta a opressão decorrente de uma relação de dominação, mas a opressão em si é uma relação dialética entre opressores e oprimidos ${ }^{8}$. Nessa relação, os oprimidos também podem incorporar a lógica opressora, em um processo de adesão que também foi identificado pelo pensador martinicano Frantz Fanon. Assim, a luta do oprimido não é somente contra o opressor, mas pela superação das relações de opressão. Para Freire帛, a finalidade da educação é criar condições de superação das opressões e injustiças presentes na sociedade.

Brandão ${ }^{7}$ aponta que, embora associada às experiências de alfabetização de adultos, é 
importante não reduzir a elas o projeto de educação popular que se consolidou nesse período, muito menos associá-lo às propostas pedagógicas de alfabetização ligadas à formação e à qualificação de mão de obra que até então eram dominantes. A educação popular inicia-se no campo da educação de adultos, mas logo passa a ser aplicada em outros campos de prática social. Nesse processo, podemos afirmar que assume as seguintes características:

- Consolida-se como um campo prático-teórico não só da educação, mas das relações sociais tendo como um ponto central a problematização, a partir da cultura, das estruturas desiguais e opressoras presentes na sociedade de forma a estabelecer condições de transformar essas estruturas;

- Ultrapassa o projeto de criação de um método educativo para as classes populares, assumindo a proposta de um trabalho educativo com o povo e a partir de seus saberes e referências;

- Reconhece a dimensão intrinsecamente política da educação e a considera como um instrumento de conscientização e politização, por intermédio da construção de outros saberes, ao invés de ser um saber dominante de efeito ajustador à ordem vigente por meio da transferência de conteúdos a sujeitos e grupos populares;

- Defende a possibilidade de realização do processo educativo em todas as situações de práticas críticas e criativas entre educadores e educandos ou em um processo de organização de classe.

Em resposta às exitosas experiências de alfabetização empreendidas por Paulo Freire e sua equipe, o governo brasileiro - que, sob a presidência de João Goulart, empenhava-se na realização de reformas de base no País aprovou, no início de 1964, a multiplicação dessas primeiras experiências por meio de um
Plano Nacional de Alfabetização, que previa a formação de educadores em massa e a rápida implantação de 20 mil núcleos - os círculos de cultura - em vários estados. O plano deveria atingir todo o País, orientado pela proposta pedagógica de educação popular sistematizada por Paulo Freire.

No entanto, essa proposta foi suprimida meses depois, ainda em 1964, com o golpe empresarial-militar e substituída pelo Movimento Brasileiro de Alfabetização (Mobral). Paludo ${ }^{5}$ aponta que o golpe de 1964 representa o êxito de um projeto de desenvolvimento do País subordinado ao grande capital internacional, assim como ocorreu em vários outros países da América do Sul no mesmo período. Nesse contexto, fortaleceu-se uma concepção de educação e de escola como aparelhos de reprodução da ordem do capital em detrimento da pedagogia crítica e emancipatória proposta pela educação popular.

Com a emergência das lutas populares pela redemocratização do Brasil, já no final de década 1970, múltiplos movimentos se reaproximam da educação popular - como os movimentos da saúde e as Comunidades Eclesiais de Base (CEB) da igreja católica -, retomando seu caráter contra-hegemônico e sua histórica ligação com os movimentos sociais. Ao longo das décadas seguintes, diversos movimentos ligados às lutas populares, como o Movimento dos Sem-Terra (MST), os movimentos em defesa da moradia, o movimento de mulheres, das populações em situação de rua, entre outros, também se aproximam da educação popular em sua dimensão emancipatória, a partir da ideia de que os sujeitos se educam por meio das práticas sociais de luta e resistência.

Nos anos 2000 e 2010, surgem novas possibilidades de retomada do fortalecimento da educação popular, inclusive institucionalmente, com a eleição de governos de centro-esquerda no Brasil e na América Latina.

Nos dias atuais, discute-se que essa perspectiva político-metodológica, além de ser percebida como um método, pode se articular com diferentes áreas, como, por exemplo, a 
saúde, além de subsidiar diversas lutas sociais e a construção de políticas públicas democráticas, participativas e voltadas aos interesses das populações historicamente oprimidas.

\section{A educação popular em saúde}

Situando o debate no campo da saúde, Vasconcelos ${ }^{10}$ aponta que a organização de movimentos populares e comunitários de saúde esteve na base do movimento da reforma sanitária brasileira da década de 1970, o qual, posteriormente, teve como desdobramento o Sistema Único de Saúde (SUS). O fortalecimento de redes de solidariedade nas comunidades e a discussão de problemas de saúde locais viabilizaram a formação de outras práticas de saúde e ajudaram a formar uma geração de profissionais e acadêmicos que lutavam contra a ditadura e a perspectiva privatista, biomédica e hospitalocêntrica. Para o autor:

Percebia-se que a atenção médica tradicional não era injusta apenas por ser oferecida de forma limitada aos pobres, mas também porque a sua racionalidade interna reforça e recria, no nível das microrrelações, as estruturas de dominação da sociedade. O seu biologicismo, o autoritarismo do doutor, o desprezo ao saber e à iniciativa do doente e seus familiares, a imposição de soluções técnicas para problemas sociais globais, o mercantilismo e a propaganda embutida dos grupos políticos dominantes são exemplos de alguns dos mecanismos entranhados na assistência à saúde oficial que se procurava superar ${ }^{10(274)}$.

Os efeitos simbólicos e concretos das práticas da chamada medicina tradicional são presentes até os dias atuais, já que a suposta dicotomia entre o saber biomédico e o saber popular acentua distanciamentos. Esse afastamento, por sua vez, tem o efeito de criar um perigoso viés no olhar de profissionais e acadêmicos em relação às diferentes formas de organização comunitária e suas buscas pela produção de cuidado.

Muitas vezes, essas populações, em especial as mais vulneráveis, passam a ser consideradas ignorantes e desinteressadas na assimilação dos conteúdos prescritos pelos profissionais de saúde e validados pela ciência, mas que pouco dialogam com a realidade de seu cotidiano. Sobre essa aparente crise entre saber acadêmico e popular, o historiador, professor e pesquisador Victor Valla desenvolveu importantes reflexões. No texto 'A crise de interpretação é nossa: procurando compreender a fala das classes subalternas', o autor se debruça sobre um tema central na educação popular: a dificuldade em reconhecer os saberes populares como válidos e legítimos em contraste com o conhecimento científico e/ou acadêmico.

Na perspectiva de Valla"1, os saberes populares são aqueles construídos a partir das experiências cotidianas de vida e trabalho das pessoas. A essas pessoas, é importante destacar uma dimensão de classe, gênero e raça: são trabalhadores e trabalhadoras que dependem de sua força de trabalho para sobreviver, negros e negras que criam cotidianamente estratégias de enfretamento do racismo estrutural da sociedade capitalista, mulheres que resistem criativamente ao patriarcado e ao machismo, enfim, aqueles e aquelas que, embora considerados periféricos ou mesmo marginais diante do que é construído como padrão na sociedade moderna capitalista, constituem a grande maioria dos sujeitos que formam a complexa e desigual realidade social brasileira.

Valla"1 aponta que a forma como profissionais de saúde e acadêmicos lidam com populações vulneráveis e em situação de pobreza é marcada por preconceitos e distanciamentos, oriundos das diferenças de classe, raça e acesso à educação formal entre profissionais de saúde e população. Valla escreveu parte de sua obra nas décadas de 1980 e 1900. Desde então, houve importantes avanços no diálogo entre a educação popular e a saúde pública com o fortalecimento da atenção básica ocorrido no País nos anos 2000, fundamentalmente 
por intermédio da expansão da ESF com a ênfase em um modelo de cuidado territorial e comunitário. Também a aprovação da Política Nacional de Educação Popular em Saúde (PNEPS), em 2013, pode ser apontada como um marco que, dentro de suas principais ações de consolidação, tem como eixo a qualificação de profissionais de saúde e de lideranças populares nas referências da educação popular.

No entanto, a crise de interpretação citada pelo autor permanece na medida em que os espaços de produção de saber, e os próprios serviços de saúde, ainda revelam em seus cotidianos muitas dificuldades no reconhecimento da legitimidade dos saberes das classes populares. A atualidade do pensamento de Valla"1 reside na defesa de que os atores populares produzem teorias explicativas da realidade, as quais não devem ser hierarquizadas tomando como parâmetro o conhecimento científico hegemônico.

$\mathrm{O}$ autor indica uma importante percepção das classes populares de que um processo efetivo de ampla e significativa mudança social não está colocado no horizonte da atual sociedade, e nos alerta que o diálogo com as classes populares não deve ser operado como um ato de benevolência ou cortesia de atores e atrizes - sejam representantes do Estado, do terceiro setor ou da academia - que atuam como mediadores nesses grupos. É necessário um diálogo de caráter freiriano, de produção de novos conhecimentos a partir do encontro de diferentes saberes. Assim, para nos aproximarmos das realidades dessas populações, é fundamental considerarmos as condições materiais, mas também as dimensões intersubjetivas, simbólicas e sociais que formam sua leitura de mundo.

A partir de Valla", entendemos que os saberes populares compartilham elementos de várias concepções de saúde e doença, entre elas, a técnico-científica, mas também a ancestralidade, os saberes transmitidos mediante tradição oral e a espiritualidade, o que aponta para a riqueza e a complexidade desses saberes. Retomando a aproximação com o campo da saúde mental, podemos dialogar, por exemplo, com a dimensão sociocultural destacada por Amarante ${ }^{\mathbf{1 2}}$ como um dos pilares da reforma psiquiátrica brasileira.

As artes, a espiritualidade e todas as demais manifestações da cultura são potentes linguagens para discutirmos a forma como lidamos cotidianamente com a diferença, o que vai além da loucura, e abrange, por exemplo, as relações que estabelecemos com as demais populações socialmente marginalizadas, como as pessoas em situação de rua, os que fazem uso prejudicial de álcool e outras drogas, as pessoas em situação de privação de liberdade e as chamadas minorias étnicas.

\section{Saúde mental e atenção psicossocial}

Yasui ${ }^{13}$ aponta que o processo de reforma psiquiátrica no Brasil se caracterizou como uma transição paradigmática entre um modelo pautado na racionalidade médico-científica para um modelo de atenção psicossocial. $\mathrm{O}$ autor descreve uma ruptura radical com o modelo asilar até então predominante por meio do questionamento de seus fundamentos, conceitos e práticas.

Desde a década de 1970, o processo de reforma psiquiátrica no Brasil promoveu uma significativa transformação no tratamento de pessoas com transtornos mentais no País. Esse processo teve como um de seus principais marcos a regulamentação da Lei $n^{0} 10.216$, de 6 de abril de 2001, que preconiza a proteção e os direitos das pessoas com transtorno mental, a extinção de leitos psiquiátricos com característica de modelo asilar, o redirecionamento do modelo assistencial com a ênfase em processos de desospitalização e a criação de uma rede de serviços substitutivos ao hospital psiquiátrico.

$\mathrm{Na}$ atenção psicossocial, a assistência não é mais entendida como um processo curativo, mas como produção de vida, de sentido e sociabilidade ${ }^{12}$. A descentralização da doença como foco de atenção e a ênfase no sujeito 
em sua integralidade modificam e ampliam o objeto de ação do cuidado, bem como movimentam as práticas instituídas, questionando as instituições totais e a segregação dessas pessoas do seu meio. Partindo dessa premissa, questiona-se também o modo pelos quais as pessoas em situação de sofrimento mental são tratadas. Uma das questões estruturantes desse modelo se baseia no fato de que a doença mental passa a ser pensada de forma a não desvincular os sujeitos dos seus contextos de vida, seja a família, o bairro, o trabalho etc.

Assim, o cuidado em saúde mental a partir da atenção psicossocial implica a construção de redes que possam operar, por intermédio da lógica intersetorial e comunitária, na perspectiva da integralidade e da redução do estigma associado ao adoecimento mental12. Para tanto, é necessária uma rede de serviços comunitários potente, que atue nos diversos contextos pelos quais circulem as pessoas em sofrimento psíquico. Dessa maneira, os Caps se tornaram um dispositivo estratégico na operacionalização da atenção psicossocial, diminuindo significativamente as longas internações em hospitais psiquiátricos por meio de uma direção de cuidado ampliada, territorial e comunitária.

Cabe destacar que a participação ativa de profissionais e gestores públicos da área de saúde mental, aliados aos usuários dos serviços e seus familiares, foi fundamental para ampliar o processo de mudança proposto pela reforma psiquiátrica. Este ultrapassou os limites da reforma meramente estrutural de serviços e da assistência, passando a propor profundas redefinições conceituais e organizacionais, revendo criticamente o papel hegemônico e centralizador do hospital psiquiátrico, de forma a garantir os direitos civis e humanos dos usuários da rede de saúde mental, assim como sua dignidade pessoal.

A partir da sistematização empreendida por Amarante 12,14,15, é possível destacarmos quatro dimensões que constituem o processo de reforma psiquiátrica brasileiro: as dimensões teórico-conceitual, jurídico-política, técnico-assistencial e sociocultural. Tomando como referência as dimensões da reforma psiquiátrica e as transformações realizadas nas últimas décadas no campo da saúde mental, consideramos que o paradigma da atenção psicossocial dialoga com a perspectiva da educação popular em diferentes esferas, entre elas, na valorização da participação popular, na problematização da hegemonia do saber técnico-científico e no consequente reconhecimento de múltiplos saberes produzidos no cotidiano de vida das pessoas.

\section{Saúde mental e educação popular: possíveis diálogos}

Para Guimarães, Veras e Carli16, a partir do processo de construção da rede de atenção psicossocial substitutiva ao modelo hospitalar no País, as questões relativas à autonomia e à liberdade se colocam como fundamentais na construção de respostas ao sofrimento mental dos cidadãos e irão nortear as reivindicações que estruturaram a reforma psiquiátrica brasileira, bem como são pilares de sustentação na proposta de educação popular de Paulo Freire.

Para as autoras, o pensamento freiriano, assim como o movimento da reforma psiquiátrica, coloca em discussão o contato com a existência e o sofrimento do sujeito e sua ligação com o corpo social, não mais para curar ou aprender, mas para a produção de vida, de sentidos, de sociabilidade e de espaços coletivos de convivência.

Nesse sentido, a proposta do cuidado em liberdade promovida pelo paradigma da atenção psicossocial é um importante ponto de diálogo entre a saúde mental e o pensamento de Paulo Freire. A partir do respeito e da generosidade nas mediações entre profissionais e usuários, categorias também apontadas por Freire como fundamentais no processo educativo, Guimarães, Veras e Carli vislumbram a possibilidade de outro entendimento em relação às situações de sofrimento psíquico, de modo que: 
[...] tanto profissional quanto o usuário se reconheçam, na oportunidade do encontro clínico, como protagonistas de ações cujas competências podem ser específicas, mas que, sobretudo, promovam a emancipação, dando novo sentido à vida ${ }^{16(100)}$.

Outro ponto de aproximação paradigmática entre a saúde mental e a educação popular é a produção de uma nova relação com o conhecimento, em que os mitos da neutralidade, do distanciamento crítico e da autonomia da ciência são colocados em questão a partir de uma atitude epistemológica crítica ${ }^{15}$. Cabe destacar que uma importante referência no campo da educação popular em saúde é o reconhecimento da determinação social, econômica e política na produção de saúde, a articulação entre teoria e prática na construção de uma perspectiva cuidadora emancipatória, a valorização da historicidade humana nos processos educativos, assim como da intersubjetividade presente nos processos de adoecimento e cura.

Para Vasconcelos ${ }^{17}$, o movimento da educação popular e a luta dos movimentos sociais pela transformação da atenção à saúde possibilitaram a incorporação, em muitos serviços de saúde, de formas de relação com a população bastante participativas que rompem com a tradição autoritária historicamente dominante na saúde.

Muitas das práticas e tecnologias hoje comumente presentes no cotidiano dos serviços de saúde mental de caráter substitutivo, por exemplo, foram criados não só a partir das experiências reformistas internacionais, como a psicoterapia institucional francesa e a psiquiatria democrática italiana, mas são também heranças das experiências comunitárias de saúde que foram incorporadas ao SUS, incluindo também o campo da saúde mental.

As realizações de assembleias, rodas de conversa, espaços coletivos com a participação de usuários, familiares e profissionais são práticas comumente encontradas nos Caps e demais serviços da rede de saúde mental na lógica da atenção psicossocial e se aproximam de modos de organização coletiva preconizados pela educação popular. Também as reuniões de equipe, recurso comumente encontrado nesses serviços, em que o processo de trabalho, a agenda de atividades, os casos clínicos são discutidos e definidos pelos trabalhadores e trabalhadoras, apontam para uma herança de participação e construção coletiva difundida por experiências com forte influência da educação popular.

Já no âmbito político-institucional, nas décadas de 2000 e 2010, mais especificamente a partir dos governos Lula e Dilma, houve um movimento de convergência entre saúde mental e educação popular no âmbito das políticas públicas em saúde, principalmente, a partir do fortalecimento da atenção básica como porta de entrada e centro articulador do SUS. A reorganização da Política Nacional de Saúde Mental por meio da Portaria no 3.088 , de 2011, que instituiu a Rede de Atenção Psicossocial (Raps), a qual aponta para a regionalização da assistência em saúde mental e para uma maior articulação com a atenção básica, ocorreu meses antes da publicação da portaria que reorganizou a atenção básica em saúde no País mediante publicação da Política Nacional da Atenção Básica (PNAB) em 2012, mas também da publicação da PNEPS, a qual institucionalizou a educação popular em saúde no âmbito do SUS. Vale destacar que as três políticas são atualizadas entre os anos de 2011 e 2013, ainda no primeiro mandato da então presidenta Dilma Rousseff.

A PNEPS-SUS foi instituída por intermédio da Portaria $n^{\circ}$ 2.761/2013 do Ministério da Saúde e tem como objetivo contribuir com a participação popular, gestão participativa, controle social, cuidado, formação e práticas educativas em saúde, orientando as suas ações por meio de seis princípios: diálogo, amorosidade, problematização, emancipação, construção compartilhada de conhecimento e compromisso com a construção do projeto democrático e popular.

Para Amarante e Nunes ${ }^{18}$, a Raps, instituída para pessoas com sofrimento ou transtorno 
mental e com necessidades decorrentes do uso de crack, álcool e outras drogas no âmbito do SUS, possibilitou uma nova dimensão ao conjunto das ações em saúde mental no SUS, cujos objetivos principais foram definidos, como: a ampliação do acesso à atenção psicossocial da população, em seus diferentes níveis de complexidade; a promoção do acesso das pessoas com transtornos mentais e com necessidades decorrentes do uso do crack, álcool e outras drogas e suas famílias aos pontos de atenção e assistência; e a garantia da articulação e integração dos pontos de atenção das redes de saúde no território, qualificando o cuidado por meio do acolhimento, do acompanhamento contínuo e da atenção às urgências.

Ao empreendermos uma breve análise das duas políticas, identificamos diálogos no que se refere ao fortalecimento de uma perspectiva de cuidado ampliada e intersetorial, a qual, até aquele momento, era uma direção política e institucional do Ministério da Saúde. Consideramos que os principais pontos de convergência entre as políticas se referem à adoção de uma concepção ampliada de saúde, ao reconhecimento da atenção básica como instância organizadora da rede de saúde e à valorização de dispositivos e tecnologias não necessariamente vinculadas ao paradigma biomédico, como os serviços de caráter comunitário e os ligados à cultura.

Embora a aprovação das portarias possa ser considerada um avanço, tanto no campo da saúde mental quanto no da educação popular em saúde, há um agudo processo de desmonte dessas políticas em curso. Esse processo teve um marco em 2015 com a negociação política do Ministério da Saúde visando à sustentação política do governo Dilma que, naquele momento, já era ameaçado pela possibilidade de impeachment. A partir de 2016, com o golpe parlamentar, institucional e midiático ocorrido no País, é possível identificar não somente descontinuidades, mas significativos retrocessos nas políticas públicas construídas nos últimos anos.

As alterações na política de saúde mental ocorridas desde então apontam para uma descaraterização da Raps por meio de elementos como a desconsideração dos avanços técnico-científicos do processo de reforma psiquiátrica brasileira, a ênfase na atenção hospitalar, a adoção de uma perspectiva conservadora no campo do álcool e outras drogas e o financiamento público de comunidades terapêuticas. Alguns autores e teóricos do campo da saúde mental19,20 e da atenção psicossocial têm denominado esse processo de contrarreforma psiquiátrica devido aos retrocessos na reforma psiquiátrica por intermédio da desconstrução de suas políticas públicas.

\section{Considerações finais}

Ao discutir os possíveis diálogos entre educação popular e saúde mental, esperamos que este texto ofereça suporte para processos críticos e reflexivos que valorizem a integralidade das ações de saúde e o compartilhamento de saberes e fazeres para a construção de caminhos férteis em relação à possibilidade de aproximação de referências que podem trazer novas contribuições para o campo da saúde pública e, mais especificamente, para a saúde mental na perspectiva da atenção psicossocial.

Acreditamos que o reconhecimento de outros saberes e visões de mundo é fundamental para criar relações de solidariedade com a diversidade e a diferença, tanto no campo da saúde mental como no da saúde pública. Neste ponto, podemos destacar que a educação popular e a atenção psicossocial têm justamente como ponto em comum o compromisso com a produção de formas de fazer ecoar vozes historicamente silenciadas.

Por fim, a aproximação entre ambas as áreas pode ainda apresentar valorosas contribuições para os atuais movimentos de resistência às crescentes ameaças à democracia, à defesa da vida e aos direitos humanos. No atual momento histórico de franco desmonte das políticas públicas de saúde, educação, seguridade, ciência e cultura, assim como do avanço do conservadorismo e da recusa radical do pensamento 
crítico, acreditamos que é imprescindível não recuarmos na defesa da potência transformadora do fortalecimento de outras perspectivas epistemológicas no campo da saúde na construção de uma ciência comprometida com a defesa da vida, da liberdade e de um projeto de sociedade mais justo e solidário.

\section{Referências}

1. Freire P. Pedagogia do oprimido. 67. ed. Rio de Janeiro: Paz e Terra; 2019.

2. Dias JVS, Amarante PD. Saúde Mental e Educação Popular: possíveis diálogos. In: Paro CA, Lemões MAM, Pekelman R, organizadores. Educação Popular e a (re)construção de práticas cuidadoras. v. 2. João Pessoa: Editora do CCTA; 2020. p. 135-154. Coletânea Educação Popular em Saúde.

3. Preiswerk M. Raíces y Plataformas de La Educación popular. In: Alejandro M, Romero MI, Vidal JR. ¿Qué es la educacional popular? La Habana: Editorial Caminos; 2008.

4. Rossato R. Praxis. In: Streck DR, Redin E, Zitkoski JJ, organizadores. Dicionário Paulo Freire - 2. ed., rev. amp. 1. reimp. Belo Horizonte: Autêntica; 2010.

5. Paludo C. Educação popular. In: Caldart RS. Dicionário da educação do campo. Rio de Janeiro: São Pauand Contributor ID).

\section{Colaboradores}

Dias JVS (0000-0003-1691-5507)* e Amarante PDC (0000-0001-6778-2834)* contribuíram igualmente para a elaboração do manuscrito.
6. Paludo C. Educação popular como resistência e emancipação humana. Cad. Cedes. 2015; 35(96):219-238.

7. Brandão CR. O que é educação popular. São Paulo: Brasiliense; 2006.

8. Restrepo E, Rojas A. Inflexión decolonial: fuentes, conceptos y cuestionamientos. Popayán: Universidade de Cauca; 2010.

9. Freire P. Conscientização. São Paulo: Cortez; 2016.

10. Vasconcelos EM. Para além do controle social: a insistência dos movimentos sociais em investir na redefinição das práticas de saúde. In: Fleury S, Lobato LVC, organizadoras. Participação, Democracia e Saúde. Rio de Janeiro: Cebes; 2010.

11. Valla V. A crise da interpretação é nossa: procurando entender a fala das classes subalternas. In: Ministério da Saúde, Secretaria de Gestão Estratégica e Participativa, Departamento de Apoio à Gestão Participativa. II Caderno de educação popular em saúde. Bra- 
sília, DF: Ministério da Saúde; 2014.

12. Amarante PD. Saúde mental e atenção psicossocial. Rio de Janeiro: Fiocruz; 2007.

13. Yasui S. Rupturas e encontros: desafios da reforma psiquiátrica brasileira. Rio de Janeiro, RJ: Editora Fiocruz; 2010.

14. Amarante PD. Loucos pela vida: a trajetória da reforma psiquiátrica no Brasil. 2. ed., rev. ampliada. Rio de Janeiro, RJ: Editora Fiocruz; 1998.

15. Amarante PD. A (clínica) e a reforma psiquiátrica. In: Amarante P. Archivos de saúde mental e atenção psicossocial. Rio de Janeiro: Editora NAU; 2003. p. 45-65.

16. Guimarães AC, Veras AB, Carli AD. Cuidado em Liberdade, um encontro entre Paulo Freire e a reforma psiquiátrica. Rev. Psicol. Saúde. 2018 [acesso em 2021 fev 12]; 10(1):91-103. Disponível em: http://pepsic.bvsalud.org/scielo.php?script=sci_arttext\&pid=S2177-093X2018000100007.

17. Vasconcelos EM. Educação popular: de uma prática alternativa a uma estratégia de gestão participativa das políticas de saúde. Physis. 2004 [acesso em 2020 nov 10]; 14(1):67-83. Disponível em: http://dx.doi. org/10.1590/S0103-73312004000100005.

18. Amarante PD, Nunes O. A reforma psiquiátrica no SUS e a luta por uma sociedade sem manicômios. Ciênc. Saúde Colet. 2018 [acesso em 2021 fev 12]; 23(6):20672074. Disponível em: http://dx.doi.org/10.1590/141381232018236.07082018

19. Lima RC. O avanço da contrarreforma psiquiátrica no Brasil. Physis. 2019 [acesso em 2021 abr 4]; 29(1):e290101. Disponível em: https://www.scielo.br/pdf/physis/v29n1/pt_0103-7331-physis-2901-e290101.pdf .

20. Nunes MO, Lima Junior JM, Portugal CM, et al. Reforma e contrarreforma psiquiátrica: análise de uma crise sociopolítica e sanitária a nível nacional e regional. Ciênc. Saúde Colet. 2019 [acesso em 2021 abr 4]; 24(12):4489-4498. Disponível em: http://www. scielo.br/scielo.php?script=sci_arttext\&pid=S1413$-81232019001204489 \& \operatorname{lng}=e n \& n r m=$ iso.

Recebido em 07/05/2021

Aprovado em 29/11/2021

Conflito de interesses: inexistente

Suporte financeiro: não houve 